\title{
Recombinant TSH-Stimulated, Radioguided Differentiated Thyroid Carcinoma Surgery
}

\author{
Michael E. Spieth, MD, Department of Radiology, Nuclear Medicine Section, Marshfield Clinic, Marshfield, Wisconsin \\ Steven B. Standiford, MD, Surgery Oncology Section, Marshfield Clinic, Marshfield, Wisconsin \\ Marjorie E. Starkman, MD, Department of Internal Medicine, Endocrinology Section, Marshfield Clinic, Marshfield, Wisconsin \\ John Gough, MS, CHP, Swedish Medical Center, Seattle, Washington
}

[See related article: 3]

\begin{abstract}
A novel approach to locating and surgically resecting occult metastatic foci in a 25-year-old female with a history of total thyroidectomy for differentiated thyroid carcinoma was attempted. Two iodine-131 (131) body scans were performed: one after the patient underwent a 2-3 week thyroxine withdrawal, and another the following week utilizing recombinant TSH-stimulation. Then the patient was treated with $151 \mathrm{mCi}$ of ${ }^{131}$, and 2 weeks later, without further hormonal manipulation, she had radioguided surgery. The two diagnostic ${ }^{131}$ | body scans were negative, but the post-therapy scan was positive. Two weeks later after pre-operative skin marking, radioguided surgery localized metastatic foci in the central compartment neck just dorsal to the suprasternal notch. No other foci were identified with the probe at surgery. At pathology, 2 of the 12 nodes were positive, as well as a $1 \mathrm{~mm}$ metastatic focus in the fat. Provocative imaging protocols, aggressive radioiodine therapy, and the novel use of radioguided surgery to attempt a cure in an ${ }^{131}$ I image-negative metastatic thyroid carcinoma patient was performed. No other cases using these combined diagnostic and therapeutic efforts have been reported in the literature.
\end{abstract}

\section{INTRODUCTION}

lodine-131 (131I) negative body scans in the follow-up of thyroid cancer patients are reported in about $25 \%$ of patients with suspected metastases. These patients have no physical examination or imaging evidence of disease, but have an elevated thyroglobulin $(\mathrm{Tg})$ on laboratory testing. There is debate as to whether these patients should even be worked up any further if their $\mathrm{Tg}$ suppresses. ${ }^{1-8}$ Multiple imaging modalities have been used both successfully and unsuccessfully in the search for their disease. ${ }^{1,9}$ Anatomic imaging such as computed tomography (CT), magnetic resonance imaging (MRI), and ultrasound are usually negative within the neck. Sometimes CT will find nodular disease in the chest. Nuclear imaging with thallium-201 (Bristol-Myers Squibb Medical Imaging Co, Billerica, NJ), technetium-99m (99mTc) sestamibi (Cardiolite ${ }^{\circledR}$, Bristol-Myers Squibb Medical Imaging Co) or tetrofosmin (Myoview ${ }^{\mathrm{TM}}$, Amersham, UK), and positron emission tomography (PET) imaging with ${ }^{18} \mathrm{~F}$ fluorodeoxyglucose (FDG) have all had varying degrees of success. ${ }^{10-29}$ Even if diagnostic imaging can localize the metastatic foci, there is no guarantee that additional surgery or radioiodine therapy will cure the patient. ${ }^{30}$

REPRINT REQUESTS:

Michael E. Spieth, MD

Department of Radiology

Section of Nuclear Medicine

Marshfield Clinic

1000 North Oak Avenue

Marshfield, Wisconsin 54449

Telephone: 715-387-7787

Fax: 715-387-7775

Email: spieth.michael@marshfieldclinic.org

\section{KEYWORDS:}

Iodine radioisotopes; Radioguided surgery;

Thyroid neoplasms; Radiotherapy 
Presented is a case of diagnostically imaging a negative patient who reverted to positive post-therapy. This is not rare, but she further underwent post-therapy radioguided surgery to successfully localize the metastatic foci. Analysis of probe response using ${ }^{131}$ I for various isotopic window settings demonstrates the device's varying response and indicates that the optimal setting for ${ }^{131} \mathrm{I}$ is not the setting provided by the manufacturer.

\section{CASE REPORT}

In Texas in 1999, a 25-year-old white female had a $2.5 \mathrm{~cm}$ thyroid nodule in the right thyroid lobe that proved to be papillary thyroid carcinoma by fine needle aspiration (FNA). After a total thyroidectomy, she received a large radioiodine dose in the hospital. She moved to Wisconsin and was seen at our facility. The follow-up physical examination revealed a well-healed scar, but no nodes or masses. She had a contrast neck CT in September 2000 that demonstrated the patient was status-post thyroidectomy and no residual thyroid tissue was seen (figure 1).

In January 2001, she underwent a routine thyroxin withdrawal ${ }^{131}$ I body scan after having been on suppression, her thyroidstimulating hormone (TSH) of 1.6 (normal 0.5-5 IU/mg) 4 weeks prior (negative scan is not shown). She was restarted on thyroxin and remained asymptomatic.

Approximately 1 year later, in January 2002, she had another routine thyroxin withdrawal negative ${ }^{131}$ I body scan (not shown). Prior to the scanning her suppressed TSH was 1.6. However, this time she had additional Tg testing that revealed a rising level to 6.6 (normal $<3.0 \mathrm{ng} / \mathrm{ml}$ in athyroid patients). This prompted an additional scan prior to replacing her on thyroxin suppression. She had one intramuscular injection of Thyrogen $^{\circledR}$ (thyrotropin alpha, Genzyme Corporation, Cambridge, MA) on both Monday and Tuesday, a $4 \mathrm{mCi}$ oral dose of ${ }^{131}$ I on Wednesday, and body imaging on Friday. The scan was again negative (scan not shown), but we had an elevated and rising $\mathrm{Tg}$ level as laboratory evidence of metastatic disease.

${ }^{131}$ I therapy was scheduled the following week. She received $151 \mathrm{mCi}$ of ${ }^{131}$ I without further recombinant TSH stimulation and one week later she had a positive post-therapy scan because of evidence of metastatic disease (figure 2). It is not routine to perform post-therapy scans in all patients, only those with occult disease. Her health status was discussed at length with the hope that ${ }^{131}$ I dose that had localized her disease would also eradicate the disease. Otherwise, this process would have to be repeated.

Another option was discussed with the patient. Our oncology surgeon has vast experience in radioguided surgeries.

However, prior to this case, the navigator probe gamma guidance system (United States Surgical Corporation, Watertown, MA) had only been used for lymphoscintigraphy in breast and melanoma surgery and in parathyroid adenoma localization. Individuals had used ${ }^{131}$ I compounds for medullary thyroid carcinoma, but not papillary or follicular thyroid carcinoma. 1,31-37 Tumor localization with the probe in position during surgery has not been previously described in the literature for differentiated thyroid carcinoma. However, the concept and surgery are similar to other radioguided procedures. The patient agreed to attempt this procedure.

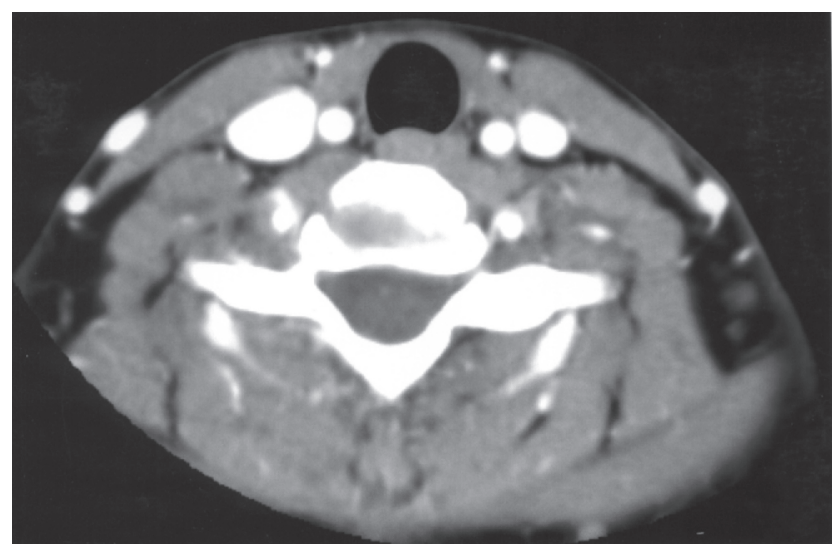

Figure 1. Negative CT scan of the neck in September 2000.

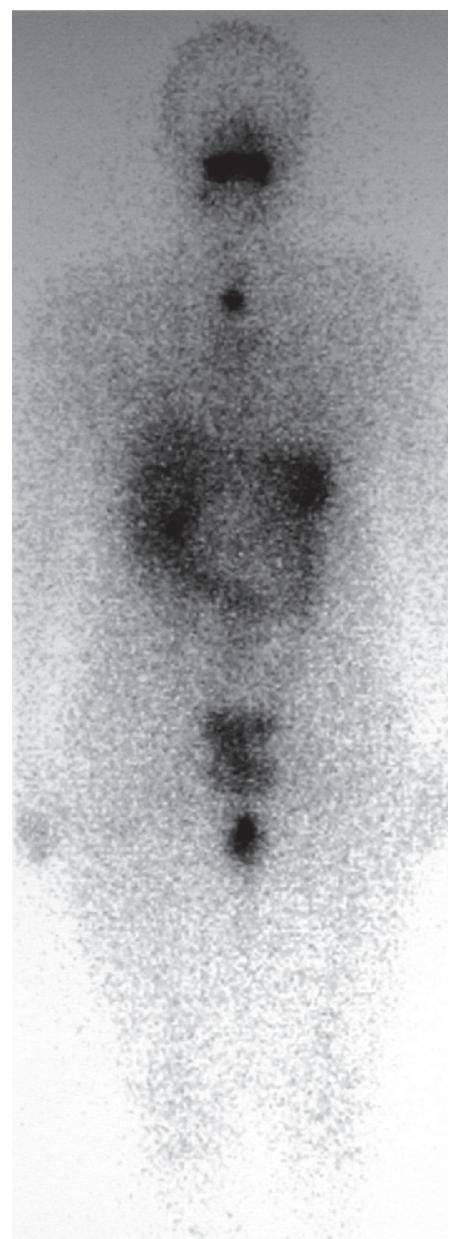

Figure 2. Post-therapy positive 131| scan in February 2002. 
Another option, sodium ${ }^{125}$ I could be an intraoperative probe option assuming you knew preoperatively where to look. ${ }^{125}$ I has such a low energy that it is not used clinically for imaging. The low energy photons may not have penetrated the sternum or clavicles that may have been helpful in this case.

The oncology surgeon was interested in operating to have a higher chance of cure. Without further stimulation or ${ }^{131} \mathrm{I}$ dosing, we performed post-therapy imaging. There was only background activity in the thyroid bed. However, near the sternal notch was a single focus of abnormal activity. We marked the skin over the suspected lesion (scan not shown). At surgery, two foci of activity were identified that read 8-12 counts per second on the ${ }^{131}$ I setting just deep to the suprasternal notch. Anatomically the counts were coming from the central compartment that had not been resected during the multiple initial surgeries. The presence of the central compartment came as a surprise since this area is usually resected in thyroid cancer patients, and this is where the skin probe activity was detected. A probe check of the neck after central compartment node removal revealed only background activity. Surgical pathology found 2 out of 12 lymph nodes positive for papillary thyroid carcinoma. In addition, a $1 \mathrm{~mm}$ foci of metastatic thyroid carcinoma was found invading fat.

The post-surgical pre-thyroxin suppression Tg level had decreased from 6.6 to 1 . She was placed back on thyroxin suppression and we continue to follow her. Several weeks after the surgery our radiation safety officer (JG) ran a series of tests on the probe (table 1). He found that the probe was most sensitive for detecting ${ }^{131}$ I with the threshold setting off instead of the on position as recommended. Unexpectedly, to completely remove any ${ }^{131} \mathrm{I}$ background detection, the most sensitive isotopic window setting for this device was indium-111 (111 In).

\section{DISCUSSION}

Not everyone agrees that every differentiated thyroid cancer patient should receive radioiodine. ${ }^{1-8}{ }^{131}$ I body scan negative differentiated thyroid carcinoma presents a difficult dilemma for both the clinician and the patient. Two possible options were presented to the patient. The first is recombinant TSH stimulated ${ }^{131} \mathrm{I}$ body scans. There is support for performing the scan while the patient is still on thyroxin. ${ }^{38}$ Nuclear medi- cine physicians would treat these patients with ${ }^{131} \mathrm{I}$ at least once and follow with the Tg. In addition, nuclear medicine physicians who use recombinant TSH, use it under selected conditions such as Tg-positive, ${ }^{131}$ I negative body scan patients only. 39

The second option is post-therapy radioguided surgery. There is a precedent for using it under multiple neoplasms and multiple radiopharmaceuticals. ${ }^{32}$ There is one article in the literature of sentinel node lymphadenectomies in thyroid malignancies found in a similar clinical setting. ${ }^{40}$ No literature for the indication presented by our patient was located, but the procedure worked well in this particular instance. The low background and tumor counts presented a unique situation for an experienced surgeon who was used to far greater count rates. In this instance an experienced user was able to successfully locate and remove the two nodes, though it is not certain whether or not the $1 \mathrm{~mm}$ fat invasion could be detected separately from the nodes because of proximity.

In conclusion, there may now be more options available for ${ }^{131}$ I scan negative thyroid cancer patients. More experience is needed to see if this exciting possibility works for many other patients.

\section{ACKNOWLEDGMENTS}

The authors thank librarian Barbara A. Bartkowiak for helping with the literature search and establishing keywords and Jane Konop for her help finding references. The authors would also like to thank Marshfield Medical Research Foundation for its support through the assistance of Alice Stargardt and Graig Eldred in the preparation of this manuscript. Finally we would like to thank Diana M. Spieth for help in preparation of the illustrations.

\section{REFERENCES}

1. Wartofsky L, Sherman SI, Gopal J, Schlumberger M, Hay ID. The use of radioactive iodine in patients with papillary and follicular thyroid cancer. J Clin Endocrinol Metab 1998; 83:4195-4203.

2. Schlumberger M, Tubiana M, De Vathaire F, Hill C, Gardet P, Travagli JP, Fragu P, Lumbroso J, Caillou B, Parmentier C. Long-term results of treatment of 283 patients with lung and bone metastases from differentiated thyroid carcinoma. J Clin Endocrinol Metab 1986; 63:960967.

Table 1. Probe readings taken on March $22,20027.5 \mathrm{~h}$ after administration of $25.3 \mu \mathrm{Ci}$ of ${ }^{131}$.

\begin{tabular}{ccc}
\hline Energy Setting Window & Reading (10 sec count) & Background (10 sec count) \\
\hline $99 \mathrm{~m}_{\mathrm{Tc}}$ & 2,878 & 0 \\
111 In & 7,355 & 0 \\
$131 \mid$ & 3,374 & 0 \\
$125 \mid$ & 3,485 & 6 \\
None & 26,636 & 0 \\
\hline \hline
\end{tabular}


3. Grant S, Luttrell B, Reeve T, Wiseman J, Wilmshurst E, Stiel J, Donohoe D, Cooper R, Bridgman M. Thyroglobulin may be undetectable in the serum of patients with metastatic disease secondary to differentiated thyroid carcinoma. Follow-up of differentiated thyroid carcinoma. Cancer 1984; 54:1625-1628.

4. Casara D, Rubello D, Saladini G, Masarotto G, Favero A, Girelli ME, Busnardo B. Different features of pulmonary metastases in differentiated thyroid cancer: natural history and multivariate statistical analysis of prognostic variables. J Nucl Med 1993; 34:1626-1631.

5. Brendel AJ, Lambert B, Guyot M, Jeandot R, Dubourg H, Roger P, Wynchauk S, Manciet G, Lefort G. Low levels of serum thyroglobulin after withdrawal of thyroid suppression therapy in the follow up of differentiated thyroid carcinoma. Eur J Nucl Med 1990; 16:35-38.

6. Spencer CA, LoPresti JS, Fatemi S, Nicoloff JT. Detection of residual and recurrent differentiated thyroid carcinoma by serum thyroglobulin measurement. Thyroid 1999; 9:435-441.

7. Pacini F, Molinaro E, Lippi F, Castagna MG, Agate L, Ceccarelli C, Taddei D, Elisei R, Capezzone M, Pinchera A. Prediction of disease status by recombinant human TSH-stimulated serum Tg in the postsurgical follow-up of differentiated thyroid carcinoma. J Clin Endocrinol Metab $2001 ; 86: 5686-5690$

8. David A, Blotta A, Bondanelli M, Rossi R, Roti E, Braverman LE, Busutti L, degli Uberti EC. Serum thyroglobulin concentrations and (131)-I whole-body scan results in patients with differentiated thyroid carcinoma after administration of recombinant human thyroid-stimulating hormone. J Nucl Med 2001; 42:1470-1475.

9. Toubert ME, Cyna-Gorse F, Zagdanski AM, Noel-Wekstein S, Cattan P, Billotey C, Sarfati E, Rain JD. Cervicomediastinal magnetic resonance imaging in persistent or recurrent papillary thyroid carcinoma: clinical use and limits. Thyroid 1999; 9:591-597.

10. Lorberboym M, Murthy S, Mechanick JI, Bergman D, Morris JC, Kim CK. Thallium-201 and iodine-131 scintigraphy in differentiated thyroid carcinoma. J Nucl Med 1996; 37:1487-1491.

11. Seabold JE, Gurll N, Schurrer ME, Aktay R, Kirchner PT. Comparison of 99m-Tc-methoxyisobutyl isonitrile and 201-Tl scintigraphy for detection of residual thyroid cancer after 131-I ablative therapy. J Nucl Med 1999; 40:1434-1440.

12. Dworkin HJ, Meier DA, Kaplan M. Advances in the management of patients with thyroid disease. Semin Nucl Med 1995; 25:205-220.

13. Burman KD, Anderson JH, Wartofsky L, Mong DP, Jelinek JJ. Management of patients with thyroid carcinoma: application of thallium-201 scintigraphy and magnetic resonance imaging. J Nucl Med 1990; 31:1958-1964.

14. Alam MS, Takeuchi R, Kasagi K, Misaki T, Miyamoto S, Iida Y, Hidaka A, Konishi J. Value of combined technetium-99m hydroxy methylene diphosphonate and thallium-201 imaging in detecting bone metastases from thyroid carcinoma. Thyroid 1997; 7:705-712.

15. Carril JM, Quirce R, Serrano J, Banzo I, Jimenez-Bonilla JF, Tabuenca O, Barquin RG. Total-body scintigraphy with thallium-201 and iodine131 in the follow-up of differentiated thyroid cancer. J Nucl Med 1997; 38:686-692.

16. Dadparvar S, Chevres A, Tulchinsky M, Krishna-Badrinath L, Khan AS, Slizofski WJ. Clinical utility of technetium-99m methoxyisobutylisonitrile imaging in differentiated thyroid carcinoma: comparison with thallium-201 and iodine-131 Na scintigraphy, and serum thyroglobulin quantitation. Eur J Nucl Med 1995; 22:1330-1338.

17. Ugur O, Kostakoglu L, Caner B, Guler N, Gulaldi NC, Ozmen M, Uysal U, Elahi N, Erbengi G, Bejdik C. Comparison of 201-T1, 99m-TcMIBI and 131-I imaging in the follow-up of patients with well-differentiated thyroid carcinoma. Nucl Med Commun 1996; 17:373-377.

18. Elser H, Henze M, Hermann C, Eckert W, Mende U. [99m-Tc-MIBI for recurrent and metastatic differentiated thyroid carcinoma.] [Article in German] Nuklearmedizin 1997; 36:7-12.

19. Lind P, Gallowitsch HJ. The use of non-specific tracers in the follow up of differentiated thyroid cancer: results with Tc-99m tetrofosmin whole body scintigraphy. Acta Med Austriaca 1996; 23:69-75.

20. Gallowitsch HJ, Kresnik E, Mikosch P, Pipam W, Gomez I, Lind P. Tc99m-tetrofosmin scintigraphy: an alternative scintigraphic method for following up differentiated thyroid carcinoma - preliminary results. Nuklearmedizin 1996; 35:230-235.

21. Harder W, Lind P, Molnar M, Mikosch P, Gomez I, Gallowitsch HJ, Kresnik E, Unterweger O, Dinges HP. Thallium-201 uptake with negative iodine-131 scintigraphy and serum thyroglobulin in metastatic oxyphilic papillary thyroid carcinoma. J Nucl Med 1998; 39:236-238.
22. Unal S, Menda Y, Adalet I, Boztepe H, Ozbey N, Alagol F, Cantez S. Thallium-201, technetium-99m-tetrofosmin and iodine-131 in detecting differentiated thyroid carcinoma metastases. J Nucl Med 1998; 39:1897-1902.

23. Yu N, Guan C, Liu Y, Yang X. [Clinical value of 99m-Tc-MIBI imaging, 131-I whole body scan and HTG determination for the follow-up of patients with differentiated thyroid carcinoma after 131-I therapy.] [Article in Chinese] Hua Xi Yi Ke Da Xue Xue Bao 1999; 30:437439.

24. Grunwald F, Menzel C, Bender H, Palmedo H, Willkomm P, Ruhlmann J, Franckson T, Biersack HJ. Comparison of 18-FDG-PET with 131iodine and $99 \mathrm{~m}$-Tc-sestamibi scintigraphy in differentiated thyroid cancer. Thyroid 1997; 7:327-335.

25. Fridrich L, Messa C, Landoni C, Lucignani G, Moncayo R, Kendler D, Riccabona G, Fazio F. Whole-body scintigraphy with 99m-Tc-MIBI, 18 F-FDG and 131-I in patients with metastatic thyroid carcinoma. Nucl Med Commun 1997; 18:3-9.

26. Feine U, Lietzenmayer R, Hanke JP, Held J, Wohrle H, MullerSchauenburg W. Fluorine-18-FDG and iodine-131-iodide uptake in thyroid cancer. J Nucl Med 1996; 37:1468-1472.

27. Dietlein M, Scheidhauer K, Voth E, Theissen P, Schicha H. Fluorine-18 fluorodeoxyglucose positron emission tomography and iodine-131 whole-body scintigraphy in the follow-up of differentiated thyroid cancer. Eur J Nucl Med 1997; 24:1342-1348.

28. Muros MA, Llamas-Elvira JM, Ramirez-Navarro A, Gomez MJ, Rodriguez-Fernandez A, Muros T, Lopez de la Torre M, Becerra A, Carreras JL. Utility of fluorine-18-fluorodeoxyglucose positron emission tomography in differentiated thyroid carcinoma with negative radioiodine scans and elevated serum thyroglobulin levels. Am J Surg 2000; 179:457-461.

29. Moog F, Linke R, Manthey N, Tiling R, Knesewitsch P, Tatsch K, Hahn $\mathrm{K}$. Influence of thyroid-stimulating hormone levels on uptake of FDG in recurrent and metastatic differentiated thyroid carcinoma. J Nucl Med 2000; 41;1989-1995.

30. Fatourechi V, Hay ID, Mullan BP, Wiseman GA, Eghbali-Fatourechi GZ Thorson LM, Gorman CA. Are posttherapy radioiodine scans informative and do they influence subsequent therapy of patients with differentiated thyroid cancer? Thyroid 2000; 10:573-577.

31. Heshmati HM, Gharib H, van Heerden JA, Sizemore GW. Advances and controversies in the diagnosis and management of medullary thyroid carcinoma. Am J Med 1997;103:60-69.

32. Jong M, Sundram FX. Two cases of medullary thyroid carcinoma. Ann Acad Med Singapore 2001; 30:646-650.

33. Obiols G, Simo R, Burgos R, Tresserras R, Galofre P, Masmiquel L, Hernandez C, Mesa J. [Differentiated thyroid carcinoma, 1972-1992. Follow-up, detection of recurrences and prognostic factors.] [Article in Spanish] Med Clin (Barc) 1997; 109:738-743.

34. Morris DM, Boyle PJ, Stidley CA, Altobelli KK, Parnell T, Key C Localized well-differentiated thyroid carcinoma: survival analysis of prognostic factors and (131)I therapy. Ann Surg Oncol 1998; 5:329337.

35. Yunta PJ, Ponce JL, Prieto M, Merino F, Sancho-Fornos S. The importance of a tumor capsule in columnar cell thyroid carcinoma: a report of two cases and review of the literature. Thyroid 1999; 9:815-819.

36. Nishida T, Nakao K, Hashimoto T. Local control in differentiated thyroid carcinoma with extrathyroidal invasion. Am J Surg 2000; 179:86-91.

37. Lin JD, Chao TC, Chen ST, Weng HF, Lin KD. Characteristics of thyroid carcinomas in aging patients. Eur J Clin Invest 2000; 30:147-153.

38. Robbins RJ, Tuttle RM, SOnenberg M, Shaha A, Sharaf R, Robbins H, Fleisher M, Larson SM. Radioiodine ablation of thyroid remnants after preparation with recombinant human thyrotropin. Thyroid 2001; 11:865-869.

39. Sherman SI, Gopal J. Thyroglobulin positive, RAI negative thyroid cancers: the role of conservative management. J Clin Endocrinol Metab 1998; 83:4199-4200.

40. Kelemen PR, Van Herle AJ, Giuliano AE. Sentinel lymphadenectomy in thyroid malignant neoplasms. Arch Surg 1998; 133:288-292. 